\title{
Gentrificación en Costa Rica: un estudio exploratorio a partir del indicador de brecha de renta
}

\section{Gentrification in Costa Rica: An exploratory study based on the income gap indicator}

\author{
Wendy Molina
}

Escuela de Sociología, Universidad de Costa Rica, San José, Costa Rica.

\section{wlmolina@uc.cl}

\section{Resumen}

En esta investigación se intenta verificar la presencia de procesos de gentrificación en la Gran Área Metropolitana de Costa Rica, a partir del análisis de los indicadores de Captura de Brecha de Renta y Expulsión Potencial de Población. Para ello se analiza el debate que existe alrededor del concepto, su aplicación en otros países latinoamericanos y sus hallazgos, así como las características del desarrollo urbano en Costa Rica desde inicios del siglo XX. Los resultados muestran que, efectivamente, en la zona rural noroeste de la ciudad, se registra captura y acumulación de brecha de renta y expulsión potencial de población en niveles muy elevados si se los compara con lo hallado en otras ciudades latinoamericanas. Finalmente, se discute acerca de uno de los hallazgos más destacables: el carácter rural de nuestra gentrificación, y la ausencia de gentrificación en zonas céntricas. Se propone que esta modalidad de la gentrificación puede comprenderse a partir del modelo de gobernanza urbana neoliberal de Costa Rica desde la década de los años 1980, el que ha marcado la tendencia de crecimiento desregulado de la ciudad, haciéndola expansiva, fragmentada y con deterioro y abandono del centro, en donde sólo se registran débiles y muy recientes procesos de renovación urbana.

Palabras clave: gentrificación, mercado de la vivienda, migración intrarregional.

\begin{abstract}
This investigation attempts to verify the presence of gentrification processes in the Greater Metropolitan Area of Costa Rica, based on the analysis of the indicators of Income Gap Capture and Potential Population Expulsion. For this, the debate that exists around the concept, its application in other Latin American countries and its findings, as well as the characteristics of urban development in Costa Rica since the early twentieth century are analyzed. The results show that, indeed, in the northwestern rural area of the city, there is a capture and accumulation of the income gap and the potential expulsion of the population at very high levels when compared to that found in other Latin American cities. Finally, one of the most remarkable findings is discussed: the rural character of our gentrification, and the absence of gentrification in central areas. It is proposed that this modality of gentrification can be understood from the neoliberal urban governance model of Costa Rica since the 1980s, which has marked the trend of deregulated growth of the city, making it expansive, fragmented and deteriorating and abandonment of the center, where only weak and very recent processes of urban renewal are registered.
\end{abstract}

Keywords: gentrification, housing market, intraregional migration.

Documento recibido el 30 de agosto de 2019 y aceptado el. 27 de abril de 2020.

Esta investigación forma parte del "Concurso Estancias de Investigación 2017-2018”, del Instituto de Investigaciones Sociales (IIS), Universidad de Costa Rica (UCR). Código 725-B7-791.

Este artículo participó en el Seminario Internacional "El Complejo Urbano Financiero-Inmobiliario en América Latina", realizado el jueves 4 y viernes 5 de abril de 2019, en Santiago de Chile, organizado y patrocinado en el marco del Proyecto Fondecyt Regular 1151287 - Investigador Principal: Ernesto López Morales, el Centro de Estudios del Conflicto y la Cohesión Social (COES), la Facultad de Arquitectura y Urbanismo de la Universidad de Chile y su Doctorado en Territorio, Espacio y Sociedad (D_TES).

Cómo citar: Molina, W. (2020). Gentrificación en Costa Rica: un estudio exploratorio a partir del indicador de brecha de renta. Revista de Urbanismo, 42, 32-51. https://doi.org/10.5354/0717-5051.2020.54277 
La actual discusión académica sobre la gentrificación en Latinoamérica se ha centrado en el debate acerca de si el concepto original de gentrificación puede ser aplicado en nuestra realidad latinoamericana, y en cómo comprender sus múltiples manifestaciones. Sin embargo, entre un número importante de autores, existe un amplio consenso sobre considerar la gentrificación como el producto de procesos económicos asociados a la globalización y liberalización de los mercados inmobiliarios en un contexto de financiarización de la economía capitalista (Borja y Castells, 2002; Brenner, 2013; De Mattos, 2005, 2006, 2016; Delgado, 2007; Harvey, 1985, 2013; Janoschka, 2002; Lees, Shin, \& López-Morales, 2016; Lefebvre, 1972; Sassen, 1991, 1994; Sennett, 2004; Salinas, 2013).

La presente investigación se adscribe a esta tesis, y tiene como objetivo analizar la gentrificación en la Gran Área Metropolitana (GAM) de Costa Rica a partir de la comprensión de los procesos de financiarización y mercantilización del espacio urbano, analizando la historia de la ciudad, y en ella la evolución de la planificación y el modelo de gobernanza urbana, asociados a las transformaciones del estilo de desarrollo económico del país. Asimismo, se pretende verificar la presencia de la gentrificación, a partir de la "medición" del indicador captura de brecha de renta y en segundo término, con el indicador de expulsión de población (Lees, Slater, \& Wyly, 2008; Neil Smith, 2012, 2015; Harvey, 2013; Lees et al., 2015, 2016).

Con este propósito, en el primer apartado se plantean los antecedentes del tema: el debate acerca de la aplicación del concepto gentrificación en Latinoamérica y los hallazgos de las investigaciones en el contexto latinoamericano, y como antecedente del contexto costarricense, la historia del desarrollo urbano del país, que da cuenta de los procesos de financiarización y mercantilización de la ciudad.

En un segundo apartado se desarrolla la metodología aplicada para la medición de la gentrificación, el cómo se calculó el indicador de captura de brecha de renta y el de expulsión de población, con base en estadísticas de la construcción y valores, así como datos censales, en escalas macro y micro de medición.
En el tercer apartado se presentan los resultados obtenidos de esa medición: la identificación de una tipología y patrones espaciales.

Y en el último apartado de discusión, se analiza por qué las tipologías y patrones observados están asociados al estilo de gobernanza urbana que se tiene en el país y que se diferencia de lo observado en otras metrópolis latinoamericanas.

La aplicación del concepto gentrificación en Latinoamérica. El concepto gentrificación -acuñado por Ruth Glass en 1964- se utilizó por primera vez para describir un proceso migratorio hacia Londres, de clases medias que venían desde la periferia de la ciudad, y se definió como la reestructuración espacial de un área urbana, en la que ocurre un desplazamiento de residentes de bajos ingresos por la llegada de población de un estrato socioeconómico superior.

Posteriormente, este concepto dio lugar a todo un campo de investigación que agrupa a una gran cantidad de autores que ha aplicado el concepto de forma diferente. Estas investigaciones han generado un fuerte debate, pues, por un lado, se cuestionan las generalizaciones que provienen de trabajos y teorías urbanas propias de la realidad anglosajona; y, por otro lado, se discute la aplicación indiscriminada a una gran diversidad de procesos de urbanización (Rojo, 2016).

En el presente trabajo, prescindiremos de la discusión teórica acerca del concepto y las diversas explicaciones que se dan del fenómeno de uno y otro lado del debate (Lees et al., 2008); y nos ocuparemos principalmente de la discusión acerca de la aplicación en Latinoamérica y, sobre todo, en los hallazgos de las investigaciones sobre la gentrificación en el contexto latinoamericano.

Quizá lo primero es señalar que, en la literatura producida hasta ahora, gana cada vez más terreno una postura síntesis que supera viejas dicotomías. Por ejemplo, entre un enfoque basado en la oferta y otro basado en la demanda, hoy día hay suficiente consenso acerca de que la gentrificación es ya un fenómeno planetario (Lees et al., 2016), que se manifiesta de múltiples formas, y que puede ser estudiado desde un campo de estudios comparativo (López-Morales, 2009). Lo que ha permitido tomar el término gentrificación en un sentido amplio, es decir, como "un concepto válido para agrupar casos geográficamente variados que muestran la 
reestructuración espacial producto de formas también múltiples de neoliberalismo, y que por ello sirve para mostrar una diversidad de prácticas de apropiación del espacio" (Casgrain y Janoschka, 2013, p.21). Y en este sentido, se entiende como un fenómeno que guarda relación directa con el capitalismo, que se puede explicar desde las estructuras capitalistas que lo generan y, por lo tanto, totalmente aplicable a Latinoamérica con sus particularidades económicas, sociológicas e institucionales (Lees et al., 2008; Lees et al., 2015, 2016; López-Morales, 2009).

A este respecto, López-Morales (2016) Ilama la atención de que, desde esta perspectiva teórica, la gentrificación debe identificarse a partir del indicador de captura de brecha de renta (como indicador estructural) $y$, además, verificar que el proceso tenga el efecto de producir desplazamiento o exclusión de los segmentos sociales más bajos (Lees et al., 2016).

Siguiendo todo lo anterior, en la investigación hasta ahora, se han identificado procesos de gentrificación en una gran diversidad de modalidades de urbanización: de naturaleza comercial, residencial, turística; y de tipo renovación, redesarrollo, verticalización (Rojo, 2016).

Desde esta perspectiva, señalan tres fases del fenómeno desde su primera aparición en los años sesenta: cuando la gentrificación se presentaba como propia de ciudades postindustriales, hasta una tercera fase en la década de 1990, en la que la gentrificación se presenta tanto en ciudades del centro como en periferias mundiales; y en el tránsito por cada una de estas fases, se aprecia la evolución de la gentrificación desde la escala local a la planetaria, desde ser un fenómeno barrial impulsado por municipios vía renovación urbana, hasta una escala regional, en donde participan tanto el Estado como el mercado, con inversión de capital financiero mundial de mayores dimensiones (Lees et al., 2008).

Asimismo, la gentrificación se asocia con una determinada configuración capitalista en la época de la globalización: la configuración financiera a partir de la década de 1970, cuando se impone la lógica financiera sobre la productiva (Borja y Castells 2002; Brenner, 2013; De Mattos, 2005, 2006, 2016; Delgado, 2007; Harvey, 1985, 2013; Janoschka, 2002; Lefebvre, 1972; Salinas, 2013; Sassen, 1991, 1994; Sennett, 2004). En ese contexto, a medida en que se fue reduciendo la disponibilidad de suelo edificable en las partes más consolidadas (y rentables) de cada espacio urbano, los inversores inmobiliarios intensificaron sus operaciones de "destrucción creativa", por las que reemplazaron partes del medio ambiente construido de baja densidad por nuevas edificaciones. (De Mattos, 2016, p. 46)

Estas operaciones permiten una importante absorción de los excedentes de capital, y originaron un tipo de negocio inmobiliario que ha tendido a multiplicarse en las grandes áreas urbanas en expansión, incluyendo Latinoamérica (De Mattos, 2016). A este respecto, otros autores también señalan la relación de estos procesos macro, con la desregulación y privatización de la gestión urbana, intensificados en Latinoamérica en las últimas tres décadas, y que en general crean las condiciones necesarias para la gentrificación y la segregación residencial socioeconómica (Borja y Castells 2002; Rodríguez, 2001; Sassen, 1991, 2007; Sennett, 2004; Silva y Castillo, 2007).

En cuanto a los hallazgos de la investigación de la gentrificación en Latinoamérica, para Casgrain y Janoschka (2013), el estudio de la gentrificación en las ciudades latinoamericanas debe considerar al menos cuatro particularidades del contexto: 1) la constante creación de nuevos mercados inmobiliarios 2) la gentrificación simbólica (restauración del patrimonio); 3) la particular debilidad en la gestión local; y 4) la fuerte presencia de luchas vecinales en contra de procesos actuales de reurbanización capitalista.

Salinas (2013), explica algunos rasgos propios de la gentrificación en Latinoamérica: son comunes los planes de repoblamiento, los procesos de rescate del patrimonio histórico y los planes de renovación o regeneración urbana, como los instrumentos generadores de procesos de gentrificación.

Por otra parte, Díaz (2013) ha identificado formas de desarrollo urbano que podrían formar parte del proceso de gentrificación, -aplicables también en Latinoamérica, desde su perspectiva-, tanto como procesos asociados o complementarios, o como fases intermedias, ya que para él la gentrificación no siempre ocurre de forma acelerada o lineal; estos son: invasión-sucesión, filtrado residencial, renovación urbana y redesarrollo. 
En relación con esto último, Contreras (2017), llama la atención acerca de la diversidad de procesos de transformación urbana que en Latinoamérica suelen suceder de forma simultánea o secuencial, y que en conjunto pueden formar parte de un proceso de gentrificación más amplio o como procesos diferentes que coexisten, por ejemplo, procesos de renovación urbana, inversión y gentrificación, al lado de otros de tugurizacion, desinversión y deterioro.

Finalmente, López-Morales encuentra en Santiago de Chile (2013), procesos deliberados de devaluación de renta de suelo socialmente capturada, una brecha de renta en aumento sostenido en el tiempo, además capturada y acumulada de forma monopólica (LópezMorales, Gasic y Meza, 2014).

Migración intrarregional y mercado de la vivienda. En este punto, es necesario introducir el tema de la migración intrametropolitana y su relación con el mercado inmobiliario, la expansión urbana y los procesos de gentrificación. En esta investigación se utiliza el indicador de expulsión potencial de población, además de otros indicadores indirectos de la gentrificación asociados a los movimientos de cambio residencial, -tal y como se detallará en el apartado metodológico-, de manera que es importante referirnos al tema desde un punto de vista de antecedentes teóricos, aunque sea de manera breve y resumida, dadas las limitaciones de espacio.

Los estudios clásicos de la migración interna consistieron en el análisis de los patrones y flujos migratorios del campo a la ciudad, al menos hasta la década de 1990. El análisis consistía en el cálculo de tasas de migración y se enmarcaba en una perspectiva teórica clásica demográfica (Herrera, 2006).

En Latinoamérica, a partir de la ronda de los Censos del 2000 (CELADE, 2008), se produce una especie de ruptura con los marcos teóricos tradicionales y se empieza a estudiar la migración interna en relación con otros nuevos factores y procesos, principalmente urbanos: patrones de crecimiento de las metrópolis, características de las ciudades y dinámica habitacional. Lo que sucedió es que, a partir del análisis de los diferentes censos latinoamericanos (que incluía los casos de Bolivia, Brasil, Chile, Costa Rica, Guatemala y México) como parte del Proyecto BID/CEPAL Migración y desarrollo: el caso de América Latina (CELADE, 2008),; se observó por primera vez, o al menos de forma más clara, la pérdida de atractivo migratorio del campo a las ciudades y el aumento de las tasas de migración a lo interno de las metrópolis. (CELADE, 2006 y 2008).

La lectura e interpretación del fenómeno giró en torno al análisis de procesos como el patrón de urbanización residencial en general, la expansión de asentamientos informales, proyectos gubernamentales de vivienda y la proliferación de barrios cerrados de estratos medios y altos, fueron los identificados y analizados como factores de la migración (CELADE, 2006). A partir de entonces, se ha venido profundizando en el análisis de los patrones de crecimiento y expansión de las ciudades y su relación con la migración interna, y se ha establecido que el concepto de zona metropolitana se ha complejizado y, entre otras transformaciones, las metrópolis se muestran ahora dispersas y fragmentadas. Esto lleva a que se explique la migración intrametropolitana y sus patrones en relación con los del crecimiento de la ciudad misma, identificando patrones de movilidad residencial y expansión urbana de tipo concentrado, disperso, de desconcentración concentrada, entre otros (Chávez et al., 2016).

En la etapa actual de los estudios de la migración, el enfoque ha virado hacia medir y explicar la migración junto con la vivienda y las transformaciones espaciales de la metrópoli, todo como parte de un mismo proceso. Ya no se habla de migración interna propiamente dicha, pues por la forma en la que se comporta el mercado de la vivienda y su impacto en la ciudad, se incluye a los inmigrantes internacionales, quienes inmigran y se localizan en zonas específicas de la ciudad de acuerdo a la oferta habitacional, y eso forma parte del proceso general de transformación de la ciudad, su morfología y funcionamiento. En este punto, se insta a trabajar de forma hermanada entre disciplinas, e intentar vincular el análisis de la migración con la vivienda y la ciudad, y con los estudios urbanos tradicionales enmarcados en disciplinas como la geografía, arquitectura, urbanismo, sociología, etc. (Chávez et al., 2016).

En el caso de Costa Rica, la literatura señala la confirmación de lo hallado para otras ciudades latinoamericanas: la dirección de los flujos migratorios es del centro a la periferia urbana. Los centros urbanos más poblados son mayormente expulsores, y los cantones periféricos que corresponden a zonas de urbanización más reciente y de ruralidad en transición a urbana, tienen altas 
tasas de inmigración (Molina, 2009). Por otra parte, se encontró que las áreas rurales dentro de la GAM o, mejor dicho, cantones del borde de la GAM del tercer anillo, de vocación agrícola, casi no participan en la migración interna, sus tasas de inmigración y emigración son muy bajas (Molina, 2009). También se identifica un fuerte flujo migratorio del centro hacia la periferia noroeste, es decir, que la migración del centro a la periferia tiene mayoritariamente la dirección este-noroeste o centronoroeste, hacia zonas rurales en transición (Molina y Barquero, 2014).

Historia del desarrollo urbano de la GAM. Para iniciar este apartado, se hace necesario señalar algunos datos que permitan comprender la naturaleza geográfica del área de estudio: la GAM.

La delimitación de la GAM se corresponde muy cercanamente con la delimitación del Valle Central, por lo que es un territorio intermontano; su área es de 1997 km², que corresponden al $4 \%$ del territorio nacional. De acuerdo con la división político-administrativa, incluye porciones de las cuatro provincias centrales y suma 31 cantones (áreas locales que corresponden a municipios) (MIVAH, 2009, citado por Molina, 2019).

Este conglomerado así concebido en el Plan GAM 1982, tiene la particularidad de contener una amplia zona rural en el borde y la periferia, aunque se considere como un todo un conglomerado urbano. De esta forma, se compone de tres anillos o áreas de planificación diferenciada de su crecimiento: el anillo central o anillo de contención urbana, el segundo anillo destinado a la producción agropecuaria y el tercer anillo reservado para la conservación ambiental (MIVAH, 2009, citado por Molina, 2019). Para el año 2007, la GAM concentraba el $54 \%$ de la población del país y en ella se producía el $80 \%$ del Producto Interno Bruto (PIB) (MIVAH, 2009, citado por Molina, 2019).

Ahora bien, como punto de partida de la historia del desarrollo urbano de la GAM, es importante establecer que, en varios sentidos, el proceso de desarrollo de la ciudad es una manifestación de los procesos de desarrollo del país. La transformación del proyecto político y económico de Costa Rica, que pasó de un modelo desarrollista (desde la primera mitad del siglo XX y hasta inicios de la década de 1980) a un modelo neoliberal en el cual se reduce la inversión pública y el tamaño del Estado, se reflejó en las políticas urbanas y en el crecimiento de la ciudad.

De esta forma, es posible identificar dos grandes períodos importantes. El primero, parte en 1949 con la elaboración del primer plan de ordenamiento urbano de la capital, y termina en 1982, con el primer plan de ordenamiento urbano de la GAM, que a su vez es la última política urbana del Estado Benefactor.

El segundo, inicia en 1983, con la eliminación por Decreto de la vigencia y aplicación legal de algunas de las partes medulares del Plan de 1982, lo que marca el inicio de la desregulación y el retiro del Estado en el desarrollo de la ciudad.

Después de la fundación de la Segunda República en 1948, se impulsó un modelo de Estado desarrollista que concentraba sus esfuerzos en la industrialización y en generar procesos de planificación del país en todas las áreas. En este contexto, en 1948 se produce el Proyecto para el desarrollo urbano de la capital de Costa Rica (Solow, 1949).

A partir de 1950 Costa Rica inicia una nueva etapa de crecimiento institucional bajo un modelo socialdemócrata, y se crea el Instituto Nacional de Vivienda y Urbanismo (INVU), así como la Ley № 4240 de Planificación Urbana (1968), y la Oficina de Planeamiento del Área Metropolitana de San José (Ley No. 4240). En 1973 se establece la "Regionalización de Costa Rica para la planificación del desarrollo y la administración", y en 1976 se inicia la elaboración del Plan DRENACA (MSJ, 2017).

Desde la década de 1960 se aceleró la expansión de la mancha construida, San José se consolida como el centro urbano que articula una dinámica mayor, y entonces se empieza a formar un espacio metropolitano con la conurbación de las áreas centrales de San José, Heredia y Alajuela (Carvajal y Vargas, 1987).

Todo este proceso de crecimiento del Estado y la ciudad fue el resultado de acciones en las que convergen actores públicos y privados, bajo la batuta de un Estado que direccionó la obtención de los beneficios económicos que traería una renta urbana para el proceso de acumulación de capital. No es casual que este proceso sucedió en la región del país que tenía una mayor y más fuerte base capitalista, y ahí se explotaron aspectos como la concentración de población, la infraestructura y redes de comunicación y la concentración de los servicios 
básicos (Carvajal y Vargas, 1987). Tal y como explica Lefebvre (1970), la concentración de la población se realiza al mismo tiempo que la de los medios de producción.

La planificación de la ciudad no tuvo exactamente la misma fuerza que la planificación del crecimiento económico, se fomentó un desarrollo y crecimiento urbano basado en la infraestructura, pero se descuidó la formación de un sistema urbano bien articulado (Brenes y Molina, 2013). En consecuencia, se identificaba un funcionamiento caótico de la ciudad y en la década de 1980 surge la iniciativa de contar con una herramienta para la planificación de la ciudad bajo un modelo de ciudad compacta, y es así cómo se elabora en 1982 el Plan Regional Metropolitano GAM 1982, Plan GAM 1982 (INVU, 1983).

Ahora bien, al igual que en otros países latinoamericanos, a partir de la década de 1980 se sucedieron en el país una serie de políticas de privatización y reconfiguración de la gestión urbana a nivel regional (GAM) (Klotchkov, 2001; Mora y Solano, 1993; Pérez, 2005, 2012), que cambiaron el rol del Estado y del sector privado en el desarrollo urbano. Justamente el recién aprobado Plan GAM de 1982 fue muy debilitado por estas políticas que marcan el inicio del retiro del Estado en materia urbana (Molina, 2019). A este respecto, diversos autores explican las transformaciones urbanas que se produjeron prácticamente en el mundo entero durante las últimas décadas, y señalan que las mismas constituyen un componente inherente a los cambios que caracterizan al desarrollo capitalista a partir de la crisis del régimen de acumulación keynesiano-fordista (De Mattos, 2016) y que están estrechamente relacionadas con la desregulación y privatización de la gestión urbana, intensificadas en Latinoamérica en las últimas décadas, y que en general crean las condiciones necesarias para la gentrificación y la segregación residencial socioeconómica (Sassen, 1991, 2007; Rodríguez, 2001; Borja y Castells 2002; Sennett, 2004; Silva y Castillo, 2007).

El inicio de los procesos de desregulación y privatización de la gestión urbana se dio cuando a partir de una declaratoria de emergencia en el tema del déficit habitacional, se decretó un estado de excepción en la legislación urbana vigente, y con ello se suspendió el Plan GAM de 1982, específicamente se permitió construir fuera del anillo de contención, en zonas agrícolas y de conservación ambiental (Mora, 2003; Pérez, 2012). Posteriormente, en 1986 se institucionaliza un modelo privado de dotación de vivienda de interés social, con la promulgación de la Ley del Sistema Financiero Nacional para la Vivienda (SFNV). Con esta ley, se migró a un modelo público-privado en el cual el Estado financia la demanda de vivienda mediante bonos, pero es la banca privada quien administra esos fondos, y las empresas constructoras privadas las que se encargan de la dotación de vivienda sin seguir ninguna directriz de planificación urbana en cuanto a localización, número o diseño (BANHVI, 2018; Pérez, 2005).

A partir de este momento, inicia el retiro del Estado en la inversión y el desarrollo urbano; desde entonces, a medida que surgen necesidades urbanas sin satisfacer, naturalmente se van creando nichos de mercado para las empresas privadas en áreas como vivienda, infraestructura, zonas verdes, centros recreativos, etc. (Brenes y Molina, 2013; Molina, 2013). En este sentido, Lefebvre explica que, en este proceso, se consolida una situación en la que la ciudad (lo que queda de ella o en lo que se convierte) es más que nunca un instrumento útil para la formación de capital (...) (Lefebvre, citado por De Mattos, 2016).

En este proceso, común al resto de países latinoamericanos, Estados Unidos constituía el referente obligado desde donde se diseñaron y materializaron las transformaciones institucionales que establecieron las condiciones para intensificar la "lógica financiera general" (De Mattos, 2016).

Por otra parte, en general durante la década de los años 1980 se inicia un proceso de cambio en el estilo de desarrollo económico y social, dando un giro neoliberal, y la reducción del Estado y las finanzas públicas da como consecuencia que las instituciones relacionadas con el urbanismo no inviertan en los proyectos del Plan GAM 1982 (Klotchkov, 2001).

Ahora bien, el viraje a un estilo de gobernanza urbana de tipo empresarial, tampoco se ha consolidado, por ejemplo los esquemas financieros que se observan en otras ciudades latinoamericanas (Contreras, 2011, 2017; Casgrain y Janoschka, 2013; López-Morales, 2013; Salinas, 2013), y que de alguna manera hacen posible procesos acelerados de gentrificación en zonas céntricas, porque facilitan dinámicas de transformación urbana como la 
renovación, rehabilitación, planes de repoblamiento, etc., con un gran apoyo en la gestión y el financiamiento, por parte del Estado y municipios. En el caso de Costa Rica, no son una realidad, pues el marco legal y las herramientas financieras necesarias, no se han creado.

En el pasado reciente, se han elaborado diferentes Planes de Ordenamiento de la ciudad (PRUGAM 20082030, PLANOT, Plan GAM 2013), -que por cierto tienen como fin actualizar el Plan GAM 1982-, en los que se ha propuesto un esquema de gobernanza que se base en alianzas público-privadas y otras herramientas de gestión mixta, así como figuras legales que permitirían al Estado y los Municipios subsidiar e invertir en proyectos urbanos, pues en el esquema legal actual no es posible. Sin embargo, estos planes no fueron aprobados pues en sus propuestas contenían otras regulaciones a la acción de los privados, que provocó que las Cámaras de la construcción se opusieran y presionaran para que no entraran en vigencia.

Actualmente, se cuenta con el plan de repoblamiento para el casco central de San José (Municipalidad de San José, 2005). Pero este plan no incluye proyectos de renovación urbana como tal, ni a ejecutar por el Estado ni por el sector privado, el planteamiento consistió solamente en modificaciones al Plan Director Urbano de San José que liberan las alturas y densidades máximas permitidas. De hecho, se ha encontrado que el casco urbano de San José permanece deteriorado y con sostenido despoblamiento, y, según datos demográficos, la población no aumenta de manera sostenida. Según datos de los últimos censos -de los años 1984, 2000, 2011, la población del cantón de San José viene disminuyendo, pasando de 309.672 en 1984, a 288.054 en 2000, y a 241.464 en 2011, y su Saldo Neto Migratorio, el segundo más alto en el país de signo negativo, es de -14.4 en el año 2011 (Molina, 2009; Barquero y Molina, 2014). De igual forma si se consideran solamente los cuatro distritos centrales, la población de la ciudad de San José alcanzó 56.000 personas en el año 2000, cifra cercana a la de la población registrada en el censo de 1927 (Rosero, 2002).

Finalmente, el Reglamento de Renovación Urbana (RRU) (INVU, 2018), se aprobó recientemente en el primer semestre del año 2018; con lo cual a la fecha se ha contado únicamente con las herramientas que ya contemplaba la Ley 4240.
Así las cosas, se ha continuado bajo un esquema de legal e institucional de la planificación urbana, que fue concebido bajo un modelo de planificación desde el Estado, pero con un Estado disminuido, desfinanciado, que es más ausente que ejecutor. No se cuenta con un marco legal que haría más expeditas y agresivas las acciones del sector privado (con subsidios, declaratorias de patrimonio, etc.), y del sector público como empresario, por ejemplo, que permitiera que el Estado o los Municipios tengan un papel gestor, inversionista, socio y financista, tal y como se opera en otras ciudades para hacer posible el repoblamiento y la renovación urbana (Contreras, 2011, 2017; Janoschka, 2013; López-Morales, 2013; Salinas, 2013).

El escenario es de una gestión urbana neoliberal, no empresarial como se observa en otras ciudades latinoamericanas. Se tiene un Estado ausente que actúa más omisión, que no financia o ejecuta proyectos, ni facilita los proyectos del sector privado. El caso de Costa Rica muestra una especie de inmovilidad en las políticas urbanas que acelerarían la gentrificación en zonas céntricas, sin que esto signifique que no haya procesos de urbanización que posiblemente estén gentrificando. Por ejemplo, es posible suponer que algunas modalidades de urbanización son inviables por ser engorrosas y no rentables para las empresas inmobiliarias, como por ejemplo la renovación de edificios desocupadosabandonados, pero queda la opción del redesarrollo y la verticalización. Todos estos elementos, permiten problematizar y hacerse preguntas acerca de las condiciones en las que los factores y procesos macro y micro de la gentrificación podrían estar actuando en el territorio (Molina, 2019).

En este punto, las preguntas que orientan la presente investigación giran en torno a la identificación y descripción de la gentrificación en el contexto nacional, si es que la gentrificación está ocurriendo. En este sentido, ¿será posible identificar tipologías de desarrollo urbano y zonas de la ciudad en las que hay procesos de gentrificación? ¿Cuál será la magnitud de la captura y acumulación de rent gap en comparación con otras ciudades latinoamericanas, así como la magnitud de la expulsión potencial de población? ¿Cuál será la importancia en cifras de los movimientos migratorios, y cuáles serán las características socioeconómicas de los migrantes de entrada y salida? 


\section{Materiales y métodos}

Tal y como se ha planteado hasta esta parte, comprendemos la gentrificación en el marco de procesos de financiarización del sistema productivo, mercantilización del territorio, y su correlato en el modelo de desarrollo y la institucionalidad estructurada alrededor de la planificación urbana.

Siguiendo esta línea, el indicador para "medir" el proceso de gentrificación desde las estructuras capitalistas que la producen, es la captura de brecha de renta, y además la expulsión de población.

Comprendemos la brecha de renta como el diferencial entre la renta futura potencial y la renta actual capitalizada, diferencia que produce un valle en la curva de valor del suelo que resulta de gran beneficio potencial para los desarrolladores inmobiliarios (Harvey, 1973, 1985, 2013; Smith, 1979, 2012, 2015; Lees et al., 2008).

El indicador de la captura brecha de renta, se obtiene a partir de dos variables: la Renta de suelo por predio vendido (RSC1) y la Renta obtenida por venta de viviendas (RSC2), y se calcula como: la brecha entre el costo de la tierra y la ganancia total (ganancia - precio de venta - valor del terreno - costos de construcción) (López-Morales et al., 2014) (ver Tabla 1).

El segundo indicador, la expulsión de población o desplazamiento exclusionario, se obtiene de estimar la cantidad de población expulsada en el proceso de gentrificación, y como el proceso puede ser relativamente lento, se prefiere estimar la expulsión potencial de población. La expulsión potencial se define como la población que de acuerdo con sus ingresos, no podría permanecer en su misma localización dados los precios comerciales de la vivienda ofertada en su zona, en un contexto de renovación y/o gentrificación (López-Morales et al., 2014). Este indicador se calcula como: proporción de la cuota hipotecaria del salario mensual (ver Tabla 1).

En cuanto a los materiales, en nuestro medio no contamos con información pública acerca del valor de los terrenos, ni las ganancias finales obtenidas por las empresas desarrolladoras, tampoco el precio comercial de las viviendas. La única fuente de esta información que se encontró fue una investigación sobre el mercado de la vivienda en la GAM, que proporciona estos datos a partir su investigación propia en fuentes primarias, en los años 2005-2006 (MIVAH, 2007).

Para el indicador de expulsión potencial de población, utilizaremos como fuente la Encuesta Nacional de Hogares, en este caso, del año 2006 para que los datos sean coherentes con la investigación del CINPE (MIVAH, 2007), de esta fuente utilizamos la variable ingreso mensual.

Por otra parte, se utilizan dos variables complementarias que se encuentran en la misma base de datos del MIVAH (2007): oferta de vivienda nueva e inversión extranjera inmobiliaria, las que permiten complementar la interpretación de los resultados de los dos indicadores base.

Ahora bien, estos datos se encuentran a nivel de cantón, de manera que la medición de la brecha de renta y la expulsión potencial de población se hace a partir de promedios, lo que constituye un acercamiento sólo aproximado, pues en la literatura consultada, el cálculo de estos indicadores se realiza a nivel de cada proyecto constructivo (López-Morales, 2013; López-Morales et al., 2014). Por esta razón, se decide realizar otra exploración de pequeña escala, con microdatos censales: la Unidad Geoestadísticas Mínima (cuadras o manzanas). Desde luego, no de los mismos indicadores de la tipología, pero sí de otras variables que de igual forma permiten acercarse al conocimiento y la comprensión de la dinámica inmobiliaria, como indicadores indirectos para comprender procesos de gentrificación.

Bajo una dimensión que hemos llamado Índice de Condiciones para la Gentrificación, se analizarán características de la urbanización y la población que indican la presencia de condiciones para que ocurran o estén ocurriendo procesos de gentrificación. Entre las condiciones del territorio se utilizan las variables: deterioro del parque habitacional; y entre las entre las condiciones socioeconómicas de la población, se utilizan las variables: envejecimiento de la población y concentración de población pobre. 


\section{Tabla 1}

\section{Operacionalización de Variables}

\begin{tabular}{|c|c|c|c|c|}
\hline Dimensiones & Subdimensiones & Variables & Indicadores & Datos y cálculos \\
\hline \multicolumn{5}{|c|}{ Indicadores de Captura de Brecha de Renta y Expulsión Potencial de Población } \\
\hline \multirow[t]{2}{*}{ Rent gap } & $\begin{array}{l}\text { Captura de renta } \\
\text { urbana }\end{array}$ & $\begin{array}{l}\text { Renta de suelo } \\
\text { por predio } \\
\text { vendido (RCS1) }\end{array}$ & $\begin{array}{l}\text { Brecha de ganancia entre el costo de la } \\
\text { tierra y la ganancia total }\end{array}$ & $\begin{array}{l}\text { RCS2 = PV - RCS1 - CC } \\
\text { (ganancia = precio de venta - valor } \\
\text { del terreno - costos de construcción) }\end{array}$ \\
\hline & & $\begin{array}{l}\text { Renta obtenida } \\
\text { por venta de } \\
\text { viviendas } \\
\text { (RCS2). }\end{array}$ & & \\
\hline $\begin{array}{l}\text { Expulsión de } \\
\text { población }\end{array}$ & $\begin{array}{l}\text { Expulsión } \\
\text { potencial }\end{array}$ & $\begin{array}{l}\text { Población } \\
\text { residente con } \\
\text { ingresos } \\
\text { insuficientes } \\
\text { para acceder a } \\
\text { vivienda nueva } \\
\text { en la zona }\end{array}$ & $\begin{array}{l}\text { La cuota hipotecaria es mayor al } 60 \% \text { del su } \\
\text { salario mensual del jefe del hogar no } \\
\text { migrante. }\end{array}$ & $\begin{array}{l}\text { Salario mensual=equivalente a la } \\
\text { ocupación en la Encuesta de Hogares } \\
\text { de } 2006 .\end{array}$ \\
\hline \multirow{2}{*}{$\begin{array}{l}\text { Dinámica } \\
\text { inmobiliaria } \\
\text { (indicadores } \\
\text { complementarios) }\end{array}$} & $\begin{array}{l}\text { Oferta de } \\
\text { vivienda }\end{array}$ & $\begin{array}{l}\text { Oferta de } \\
\text { vivienda nueva }\end{array}$ & $\begin{array}{l}\text { Porcentaje de vivienda nueva por cantón } \\
\text { del total GAM entre } 2001 \text { y } 2006\end{array}$ & PRUGAM \\
\hline & Inversión & $\begin{array}{l}\text { Inversión } \\
\text { extranjera } \\
\text { inmobiliaria }\end{array}$ & $\begin{array}{l}\text { Incremento de la inversión extranjera } \\
\text { inmobiliaria (porcentaje por cantón del } \\
\text { total GAM entre } 2004 \text { y 2005) }\end{array}$ & PRUGAM \\
\hline \multicolumn{5}{|c|}{ Índices de Gentrificación } \\
\hline \multirow[t]{3}{*}{$\begin{array}{l}\text { Índice de } \\
\text { Condiciones para } \\
\text { la Gentrificación }\end{array}$} & $\begin{array}{l}\text { Características } \\
\text { urbanas }\end{array}$ & $\begin{array}{l}\text { Deterioro del } \\
\text { parque } \\
\text { habitacional }\end{array}$ & Proporción de viviendas en mal estado & $\begin{array}{l}\text { Viviendas en mal estado en paredes, } \\
\text { techo y piso. }\end{array}$ \\
\hline & $\begin{array}{l}\text { Características de } \\
\text { la población }\end{array}$ & $\begin{array}{l}\text { Envejecimiento } \\
\text { de la población }\end{array}$ & $\begin{array}{l}\text { Proporción de hogares No migrantes, con } \\
\text { jefe adulto mayor }\end{array}$ & $\begin{array}{l}\text { Número de jefes de hogar residentes } \\
\text { habituales con edades superiores a } \\
\text { los } 65 \text { años }\end{array}$ \\
\hline & & $\begin{array}{l}\text { Concentración } \\
\text { de población en } \\
\text { condición de } \\
\text { pobreza }\end{array}$ & $\begin{array}{l}\text { Proporción de población residente en } \\
\text { condición de pobreza }\end{array}$ & $\begin{array}{l}\text { Número de jefes de hogar No } \\
\text { migrantes con años de educación } \\
\text { inferiores a } 12 \text { (proxy de ingreso y } \\
\text { proxy de nivel educativo de } \\
\text { secundaria completa). }\end{array}$ \\
\hline \multirow[t]{2}{*}{$\begin{array}{l}\text { Índice de } \\
\text { Condiciones para } \\
\text { la Gentrificación }\end{array}$} & Inmigración & $\begin{array}{l}\text { Razón de } \\
\text { Inmigrantes }\end{array}$ & $\begin{array}{l}\text { Número de inmigrantes por número de } \\
\text { residentes }\end{array}$ & $\begin{array}{l}\text { Número de jefes de hogar } \\
\text { Inmigrantes / número de jefes de } \\
\text { hogar No migrantes }\end{array}$ \\
\hline & $\begin{array}{l}\text { Urbanización } \\
\text { reciente y } \\
\text { movilidad } \\
\text { residencial }\end{array}$ & $\begin{array}{l}\text { Tipología y } \\
\text { Tenencia de la } \\
\text { vivienda de la } \\
\text { población } \\
\text { migrante }\end{array}$ & $\begin{array}{l}\text { Proporción de jefes de hogar Inmigrantes } \\
\text { con vivienda en edificio o en condominio, } \\
\text { propia pagando a plazos. }\end{array}$ & $\begin{array}{l}\text { Proporción del tipo de viviendas de } \\
\text { hogares inmigrantes }\end{array}$ \\
\hline
\end{tabular}

*El porcentaje fue definido a partir de datos del MIVAH (2007).

Fuente: Ministerio de Vivienda y Asentamientos Humanos (MIVAH), 2007. Estudio Económico de la GAM, Diagnóstico Mercado de la Vivienda. Centro Internacional de Política Económica (CINPE), Universidad Nacional (UNA). 
Bajo la dimensión que hemos llamado Índice de Gentrificación en Proceso, se analizarán las características de la población que indican urbanización reciente y movilidad residencial de población. Se consideran las siguientes variables: razón de inmigrantes y tipología y tenencia de la vivienda de la población migrante.

En esta segunda fase, el procesamiento de datos censales se realiza mediante el software SPSS, y la cartografía mediante Quantum GIS.

\section{Resultados}

Sobre la base de esta metodología y los datos obtenidos, se logró determinar una tipología que consiste la clasificación de zonas de la ciudad de acuerdo con una combinación de sus niveles de captura de brecha de renta urbana y expulsión potencial de población: Tipo 1, zona noroeste de la GAM; Tipo 2, zona limítrofe este y oeste de la GAM; y Tipo 3, zona centro-noreste de la GAM.

El Tipo 1. Incluye los cantones de San José, Escazú, Santa Ana, Curridabat, Heredia, Barva, Santo Domingo, Santa Bárbara, San Rafael, San Isidro, Belén, Flores, San Pablo. En esta zona se registraron elevadas brechas de renta y gran expulsión potencial de población.

En esta zona (Figura 1), la empresa inmobiliaria obtiene una ganancia final de hasta 471.947 colones por $\mathrm{m}^{2}$; la brecha de renta alcanza capturada, es de hasta 431.374 colones por $\mathrm{m}^{2}$. Esto significa que la ganancia final obtenida por la empresa inmobiliaria es de hasta un $1163 \%$ con respecto a la obtenida por el propietario original en la venta del terreno (Ver Tabla 2).

\section{Figura 1}

Tipología según niveles de captura de brecha de renta y expulsión potencial de población

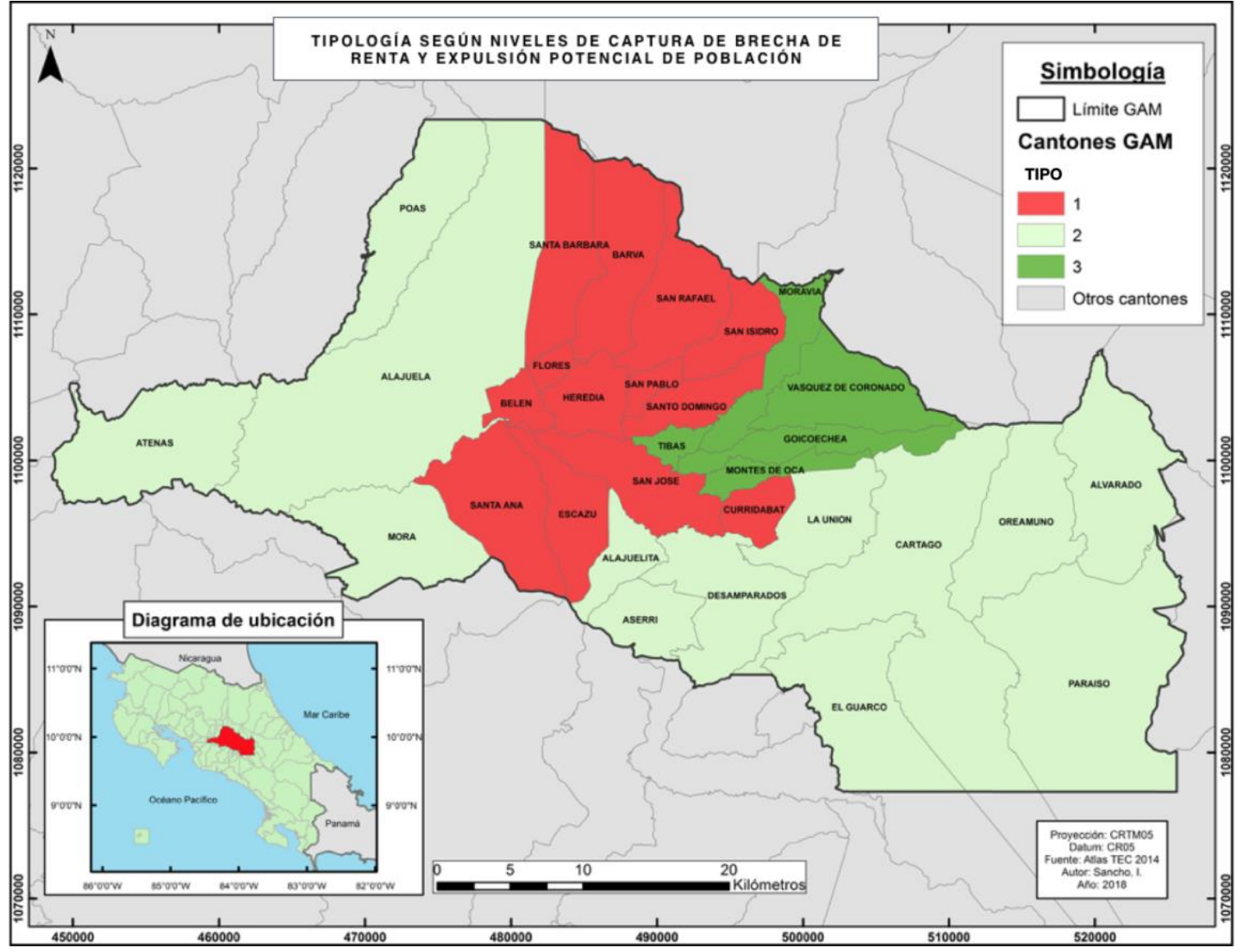

Fuente: Elaboración propia. 
Tabla 2

Tipología según niveles de Captura de Brecha de Renta y Expulsión Potencial de Población. Cantones GAM, año 2006

\begin{tabular}{|c|c|c|c|c|c|}
\hline Cantón & $\begin{array}{c}\text { Renta de suelo por } \\
\text { predio vendido (RSC1) } \\
\text { (colones/m2) }\end{array}$ & $\begin{array}{l}\text { Renta obtenida por } \\
\text { venta de vivienda } \\
\text { (RSC2) (colones/m2) }\end{array}$ & $\begin{array}{c}\text { Captura de Brecha } \\
\text { de Renta } \\
\text { (colones/m2) }\end{array}$ & $\begin{array}{c}\text { Captura de Brecha de } \\
\text { Renta en Porcentaje } \\
\text { (colones/m2) }\end{array}$ & $\begin{array}{c}\text { Expulsión Potencial } \\
\text { de Población en } \\
\text { Porcentaje }\end{array}$ \\
\hline \multicolumn{6}{|l|}{ Tipo 1} \\
\hline San José & 52.775 & 147.364 & 94.589 & 279 & 199 \\
\hline Escazú & 60.791 & 456.032 & 395.241 & 750 & 266 \\
\hline Santa Ana & 35.186 & 394.214 & 359.028 & 1120 & 567 \\
\hline Curridabat & 40.573 & 471.947 & 431.374 & 1163 & 276 \\
\hline Heredia & 42.730 & 32.121 & -10.609 & 75 & 136 \\
\hline Barva & 19.163 & 31.662 & 12.499 & 165 & 148 \\
\hline Santo Domingo & 19.163 & 31.662 & 12.499 & 165 & 133 \\
\hline Santa Bárbara & 19.163 & 31.662 & 12.499 & 165 & 166 \\
\hline San Rafael & 19.163 & 31.662 & 12.499 & 165 & 146 \\
\hline San Isidro & 19.163 & 31.662 & 12.499 & 165 & 146 \\
\hline Belén & 53.987 & 463.470 & 409.483 & 858 & 329 \\
\hline Flores & 19.163 & 31.662 & 12.499 & 165 & 132 \\
\hline San Pablo & 19.163 & 31.662 & 12.499 & 165 & 119 \\
\hline \multicolumn{6}{|l|}{ Tipo 2} \\
\hline Desamparados & 19.265 & -235.284 & -254.549 & -1221 & 38 \\
\hline Aserrí & 15.900 & -205.000 & -220.900 & -1289 & 41 \\
\hline Mora & 15.900 & -232.282 & -248.182 & -1461 & 32 \\
\hline Alajuelita & 21.724 & -198.930 & -220.654 & -916 & 43 \\
\hline Alajuela & 13.151 & -249.579 & -262.730 & -1898 & 38 \\
\hline Atenas & 13.151 & -249.579 & -262.730 & -1898 & 38 \\
\hline Poás & 13.151 & -249.579 & -262.730 & -1898 & 44 \\
\hline Cartago & 12.984 & -242.388 & -255.372 & -1867 & 36 \\
\hline Paraíso & 12.984 & -242.388 & -255.372 & -1867 & 42 \\
\hline La Union & 12.984 & -242.388 & -255.372 & -1867 & 34 \\
\hline Alvarado & 8.410 & -215.884 & -224.294 & -2567 & 54 \\
\hline Oreamuno & 12.984 & -242.388 & -255.372 & -1867 & 41 \\
\hline El Guarco & 8.410 & -215.884 & -224.294 & -2567 & 38 \\
\hline \multicolumn{6}{|l|}{ Tipo 3} \\
\hline Goicoechea & 56.771 & -149.993 & -206.764 & -264 & 92 \\
\hline Vázquez de Coronado & 56.771 & -149.993 & -206.764 & -264 & 87 \\
\hline Moravia & 56.771 & -149.993 & -206.764 & -264 & 79 \\
\hline Montes de Oca & 56.771 & -78.824 & -135.595 & -139 & 68 \\
\hline Tibás & 56.771 & -149.993 & -206.764 & -264 & 85 \\
\hline
\end{tabular}

Fuente: elaboración propia con datos del MIVAH, 2007. 
En cuanto a la expulsión potencial de población, si consideramos el precio comercial de la vivienda de la zona, esto es: desde los 220000 dólares, es decir, desde 1.701 dólares el $\mathrm{m}^{2}$, y consideramos su respectiva cuota hipotecaria, y el salario promedio de la población, resulta que las cuotas representan desde un 199\% hasta un 567\% del salario mensual de los residentes.

A este respecto, el estudio del CINPE (MIVAH, 2007), señala que la oferta de vivienda en estas zonas está dirigida a los últimos dos quintiles de ingreso, y que por sus características y acabados, son viviendas de lujo de muy altos precios.

En esta zona, hay una gran dinámica inmobiliaria, su desarrollo se inició en la década de los 1990 a partir de la

El Tipo 2. Incluye los cantones de Alajuela, Atenas, Poás, Mora, Alajuelita, Desamparados, Aserrí, Cartago, Paraíso, La Unión, Oreamuno, El Guarco y Alvarado. En esta zona no se registra brecha de renta, pues el cálculo de la ganancia total por el inmobiliario da como resultado un número negativo. Tampoco se registra expulsión potencial de población pues las cuotas hipotecarias representan el $44 \%$ o menos, de los salarios de los residentes.

Es muy importante recalcar, que este dato no quiere decir que hay construcción sin ganancia, quiere decir que, considerando el precio promedio de la vivienda en la zona, y el valor de los terrenos, la construcción no es rentable; de hecho, para el período de estudio (2005-2006), se registra una oferta de vivienda baja.

Sin embargo, llama la atención el gran aumento de la inversión extranjera inmobiliaria en los cantones de Cartago en el período en estudio. Este aumento va de un $220 \%$ hasta un $2380 \%$; e igualmente en el caso de Atenas, en donde el aumento es del $430 \%$, en ambos casos, superior al del Tipo 1.

Dado este aumento en la inversión, pero no en la oferta de vivienda, se podría afirmar intuitivamente, que la inversión fue en compra de terrenos, es por eso por lo que aún no hay captura de brecha de renta ni expulsión potencial de población, el mercado de vivienda sigue su patrón tradicional y crecimiento "natural", al menos hasta 2006.

Efectivamente, en los años posteriores al período en estudio, como sabemos, la zona de Cartago se ha urbanizado aceleradamente. También sabemos que, en urbanización de zonas agrícolas, principalmente con condominios cerrados horizontales y verticales, en lo que se refiere a Escazú y Santa Ana. Unos años más tarde Heredia, también bajo la figura del condominio, pero en mucho también sin mediar cambio de uso del suelo a urbano y utilizando la figura de la parcela agrícola en un desarrollo de baja densidad. Y por otro lado en Paseo Colón y Sabana, en el centro urbano, en los que se inició hace unos quince años, el crecimiento vertical y el redesarrollo.

Entre 2005 - 2006, el incremento en la Inversión extranjera inmobiliaria en esta zona Tipo 1 fue de hasta un $500 \%$; y el $34 \%$ de la oferta de vivienda de toda la GAM se localizó en esta zona.

los años posteriores, los planes reguladores de Cartago fueron actualizados, y en esa actualización hay una cantidad importante de tierras con cambio de uso de rural a urbano. Lo mismo ha sucedido en la zona a lo largo de la Ruta 27 desde la apertura de la carretera, lo que se verifica en los hallazgos para Atenas.

El Tipo 3. Incluye los cantones de Goicoechea, Vásquez de Coronado, Tibás, Moravia, Montes de Oca. Al igual que en el tipo anterior, en esta zona no se registra brecha de renta, pues el cálculo de la ganancia total por el inmobiliario da como resultado un número negativo. No hay captura de brecha de renta porque el precio de las viviendas no es muy elevado, en promedio en el cantón, y sin embargo el valor de los terrenos no es bajo, por tratarse de zonas urbanas céntricas.

Al igual que en el tipo 2, la oferta de vivienda en esta zona es baja.

Por otra parte, sí hay expulsión potencial de población. Las cuotas hipotecarias son bastante más bajas que las del tipo 1, pero representan entre un $68 \%$ y un $92 \%$ de los salarios de la población residente.

La diferencia importante con el Tipo 2, es que acá más bien se registra un decrecimiento en la inversión extranjera inmobiliaria (excepción es Moravia), y aquí no hay condiciones favorables para la construcción vía expansión de la frontera urbana sobre áreas rurales, pues se trata de cantones urbanos consolidados y antiguos.

\section{Condiciones para la Gentrificación}

Por otra parte, en el acercamiento de escala local a partir del microdato censal, los datos muestran un mosaico 
dentro de los tipos anteriores, pues el territorio no es homogéneo. Los tipos anteriores se calcularon con promedios cantón, y esta vez los datos son por cuadra o manzana, y justamente el objetivo era tener un nivel de detalle que permitiera capturar la variedad y diversidad dentro de la tipología de escala mayor. Y, sin embargo, mirando la tendencia general que señalan unos y otros datos, macro y micro, no hay contradicción (ver Figura 2).

Con respecto al Índice de Condiciones para la Gentrificación, se utilizaron indicadores que si bien están asociados a áreas deterioradas (y céntricas) (como viviendas deterioradas, población envejecida y concentración de población pobre), lo cierto es que las zonas rurales de la GAM obtuvieron los puntajes más altos.

Estos resultados no contradicen lo hallado en la tipología cantonal, en la cual las zonas rurales de Alajuela y Cartago, del Tipo 2, presentan gran inversión inmobiliaria (y urbanización posterior a este estudio). Asimismo, las zonas rurales del Tipo 1 puntúan alto en este Índice de Condiciones para la Gentrificación.

\section{Figura 2}

Indicador de Condiciones para la Gentrificación

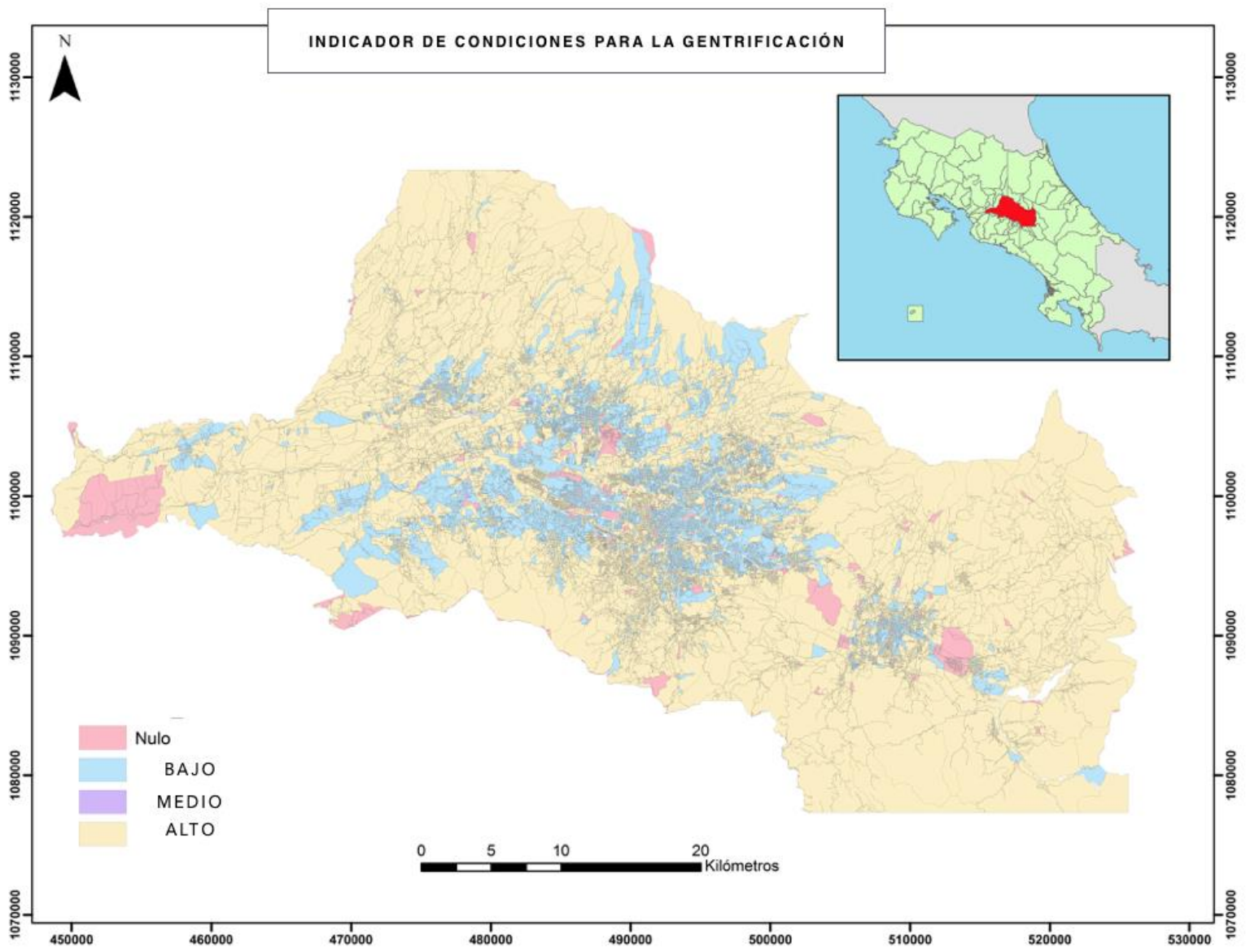

Fuente: GAM 2006. 
Ahora bien, dentro de cada tipo, merece la pena un análisis caso a caso eligiendo barrios de interés. No sería adecuado interpretar la escala micro como una tendencia regional, y justamente ese papel lo cumple la tipología macro, y más bien sobre estas zonas cabe un estudio más detallado.

\section{Gentrificación en Proceso}

Siguiendo esto último, el Índice de Gentrificación en Proceso se presenta también en zonas rurales, lo que coincide con la tipología y el índice anterior (ver Figura 3 ).

Este Índice de Gentrificación en Proceso, se diseñó y utilizó para identificar pequeñas zonas y barrios, que serían las "zonas calientes" a donde identificar una dinámica inmobiliaria más clara, que fuera "una pista" del proceso de gentrificación, por ejemplo, el haber utilizado una variable que capturara al mismo tiempo indicadores de urbanización reciente y movilidad residencial-. $Y$ en efecto, estas zonas calientes resultantes, corresponden a 27 Unidades Geoestadísticas Mínimas (o cuadras), y todas ellas se encuentran en el Tipo 1.

Mediante una búsqueda por GoogleEarth, localizamos estas 27 "manchas", y nos encontramos con condominios cerrados, y torres de apartamentos en Curridabat, Escazú, Santa Ana, Sabana, Flores, San Pablo, entre otros. Es decir, zonas calientes en las que presumimos que la captura de brecha de renta y expulsión potencial de población son elevadas, coincidiendo con que son elevadas en toda la zona como tal, del Tipo 1. Además, los otros datos censales las muestran como zonas con alta inmigración reciente, en donde quienes llegan a vivir tienen niveles educativos superiores a los residentes habituales, y además quienes han llegado recientemente habitan viviendas de tipo condominio o edificio y con tenencia de vivienda de tipo propia pagando a plazos.

\section{Figura 3}

Índice de Gentrificación en Proceso

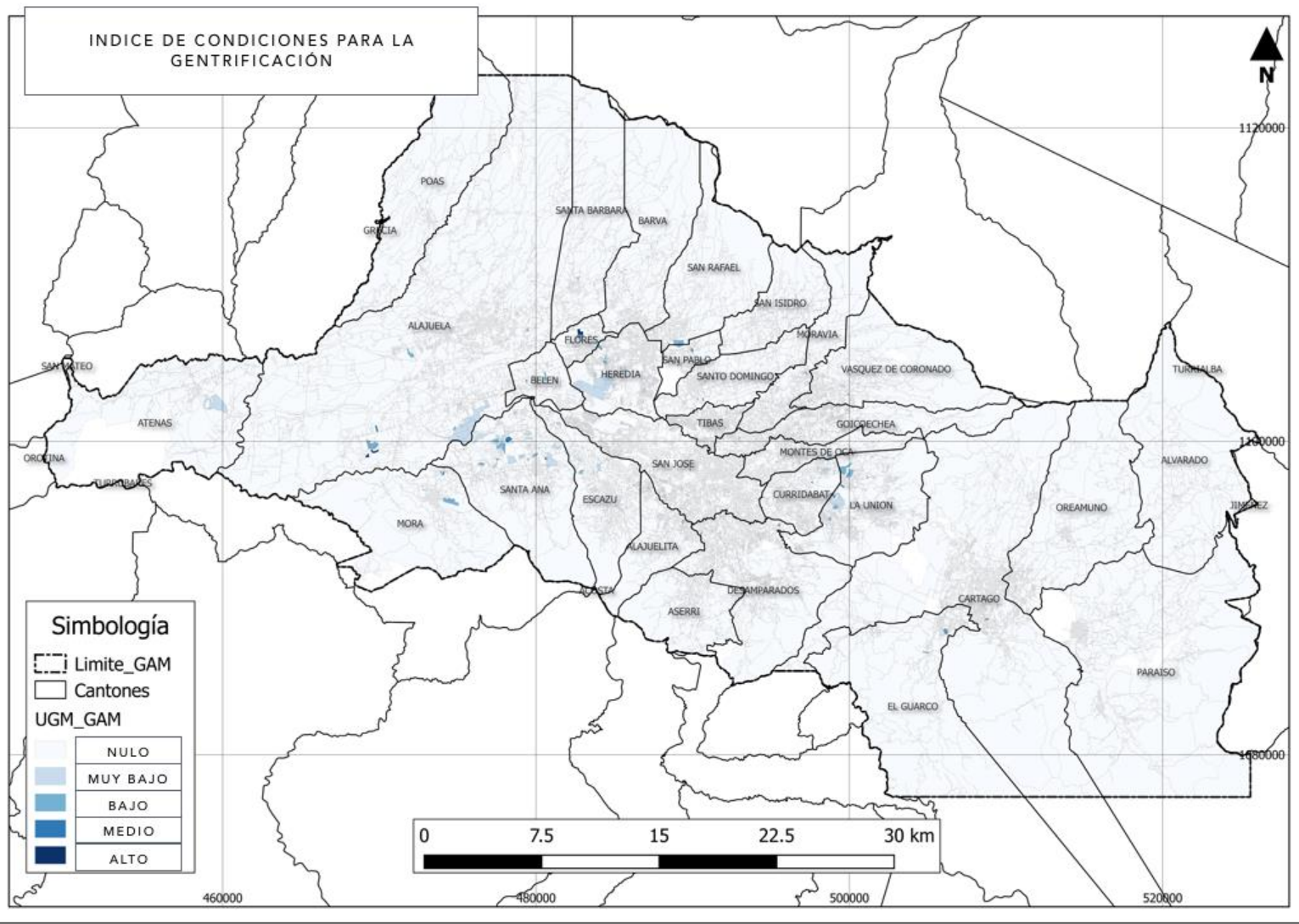




\section{Discusión}

Los resultados obtenidos por la tipología deben comprenderse como una tendencia muy general, ya que fueron calculados a partir de promedios por cantón, y en esa medida constituyen una primera aproximación a la "medición" de la gentrificación en Costa Rica.

Si somos autocríticos y desde una lectura conservadora de los datos, bien podríamos abstenernos de determinar la presencia de gentrificación en la GAM, y más bien hablar de una tenencia del mercado inmobiliario que nos brinda indicadores de las zonas que podrían estar en procesos de gentrificación. Pero también es posible considerar que el indicador de brecha de renta es suficiente para hablar de gentrificación, pues él en sí mismo da cuenta de un proceso de captura, acumulación y desposesión, y nos inclinamos por esto último.

Siguiendo esta línea, los resultados obtenidos muestran una situación en la que las zonas rurales de la GAM son tanto la promesa como la realidad de la urbanización reciente.

En este sentido, el caso de Costa Rica presenta particularidades con respecto a lo observado en el contexto latinoamericano, y estas particularidades deben discutirse a fin de comprender lo que está sucediendo e interpretarlo de manera adecuada.

A la fecha, los planes de densificación, repoblamiento y renovación de la capital $-\mathrm{y}$ los centros urbanos de la GAM o de ciudades secundarias-, aún están en proceso; asimismo, el Reglamento de Renovación Urbana (RRU) (Reglamento 6259), se aprobó muy recientemente, en el primer semestre del año 2018, con lo cual, a la fecha se cuenta con limitadas herramientas concretas de gestión y financiarización para procesos de renovación, repoblamiento y densificación (Molina, 2019a).

Lo que se tiene al día de hoy es una serie de incentivos que ha implementado la Municipalidad de San José, para el desarrollo vertical, es decir, la liberación de las alturas y las densidades, lo que ha dado como resultado, más bien un proceso de construcción acelerada y ciertamente verticalización, pero de tipo redesarrollo, no de tipo renovación. El parque habitacional y en general la edificación del casco central de San José y otros centros urbanos periféricos, permanecen intactos desde hace décadas (Molina, 2019b).
En este punto, y a la luz de los resultados obtenidos, es evidente que los procesos de producción y captura de brecha de renta y de expulsión de población no se han producido en áreas urbanas. $Y$, volviendo a lo expuesto en los antecedentes, entendemos que el esquema de gobernanza urbana no favorece la gentrificación en zonas céntricas, o al menos una tipología de gentrificación de concepto clásico (Molina, 2019a).

La tipología cantonal que obtuvimos, es el resultado de lo que está sucediendo en una amplia zona rural en transición, en la que un área agrícola al este de la ciudad, aún no urbanizada desde luego, sufre cambios en el uso del suelo y atrae una enorme inversión inmobiliaria (en proceso actualmente, pues al momento de recogida de los datos, no habían numerosas construcciones), y por otro lado, al oeste de la ciudad, este proceso inició hace unas dos décadas y ya está consolidado. Además de un área urbana y céntrica, de antiguo desarrollo, que no recibe inversión inmobiliaria.

Ahora bien, hay proyectos en ciernes, que vale la pena mencionar a fin de reflexionar sobre el futuro de las zonas céntricas. Por ejemplo, el Proyecto "Ciudad Gobierno, Eje de Renovación Pacífico-Plaza Víquez", financiado por el Banco Interamericano de Desarrollo (BID, 2017) y gestionado por la Municipalidad de San José, promueve un agresivo plan de renovación urbana en los barrios antiguos de Los Ángeles, La Dolorosa, La Soledad, La Cruz, San Cayetano y Cristo Rey. (Molina, 2019a).

Sin embargo, el recién aprobado Reglamento de Renovación Urbana, presenta algunas debilidades para la financiarización y el desarrollo de proyectos de esta naturaleza. Algunos "especialistas en planificación urbana consideran que aún tiene debilidades en cuanto a mecanismos e instrumentos de gobernanza urbana de tipo empresarial, y sigue manteniéndose en un esquema basado en la desregulación" (Molina, 2019a).

Otros proyectos en áreas centrales que se visualizan en el paisaje urbano son los que ocurren en barrios como Escalante y Aranjuez, éstos son de tipo renovación comercial, y empiezan a presentar también verticalización por redesarrollo, al menos unas cuatro torres en los últimos seis meses. Barrio Luján, un barrio obrero con gran deterioro y abandono producto de inundaciones, empieza a ocuparse con torres. Barrio Los Yoses, con avanzado envejecimiento y despoblamiento, tiene una importante 
inmigración de población joven de clase media y gran desarrollo de emprendimientos de arte y diseño, etc. (MOPT, 2015). Todos estos barrios, periféricos al casco central de San José, son continuos y no abarcan más de 3 $\mathrm{km}$ a lo largo de la vía principal que los conecta; toda la zona en cuestión está posicionada como "barrio de moda" (Asociación de Vecinos de Los Yoses, 2017).

\section{Conclusiones}

La tipología cantonal es el resultado de lo que está sucediendo en una amplia zona rural en transición, en la que un área no urbanizada (Tipo 2), sufre cambios en el uso del suelo y atrae una enorme inversión inmobiliaria; y otra área (Tipo 1), en la que este proceso inició hace unas dos décadas y ya está consolidado. Además, una tercera área (Tipo 3) urbana y céntrica, saturada, de antiguo desarrollo, que no recibe inversión inmobiliaria.

Si me miran los datos a pequeña escala, las condiciones para la gentrificación están también mayormente en las zonas rurales, y las pequeñas manchas de desarrollos inmobiliarios también se encuentran en la ruralidad de la GAM, mayoritariamente, en la parte exterior del anillo de contención. Cabe destacar que en la exploración de pequeña escala encontramos que esta urbanización se produce bajo la figura del condominio cerrado con cambio de suelo de rural a urbano, pero también sin hacer cambios en el uso del suelo mediante la normativa de parcela agrícola, con el desarrollo de viviendas independientes horizontales en propiedades de gran tamaño.

Por lo tanto, si utilizamos un concepto amplio de gentrificación basado únicamente en la captura de brecha de renta, podríamos denominar la gentrificación de la GAM de Costa Rica como rural, y caracterizarla y explicarla como el producto de unas condiciones muy particulares. De otra parte, bien podríamos afirmar que no hay gentrificación en Costa Rica a la fecha.

Pero, nos inclinamos por definir que sí hay gentrificación en Costa Rica, que la gentrificación en la GAM es básicamente rural, y se basa en la captura y acumulación de la brecha de renta obtenida de suelos de bajo costo (de uso agrícola), y la venta de viviendas de altísimo costo (en zonas rurales en transición).

Siguiendo lo señalado por diversos autores latinoamericanos (Díaz y Salinas, 2016; Janoschka, 2016), el concepto gentrificación es útil para mostrar y denunciar formas variadas de apropiación del espacio urbano, así como la desposesión y expulsión de población que conlleva el captura y acumulación de brecha de renta (López-Morales, 2016) y, es por esto, que consideramos que es pertinente señalar la singularidad de la gentrificación en Costa Rica, antes que afirmar que no hay gentrificación.

En este sentido, es importante resaltar que nuestra gentrificación está presente al noroeste de la GAM en terrenos que antiguamente fueron cafetales; que la captura de brecha de renta es muy superior a lo hallado en Santiago de Chile (López-Morales, 2013; LópezMorales et al., 2014); que la expulsión potencial de población también es abrumadora si se la compara con lo hallado en Santiago; que los procesos gentrificadores se desarrollan gracias a un Estado y municipios que por medio de la desregulación y el dejar hacer, facilitan la libre acción de las empresas inmobiliarias privadas. En este sentido, la gentrificación parece producirse en una especie de "paraíso inmobiliario" en donde el "volteo" de tierras rurales y la especulación, generan brechas de renta insólitas.

Por otra parte, como la gentrificación se presenta principalmente en zonas rurales y no asociada a la renovación urbana de zonas céntricas, el caso de la GAM de Costa Rica presenta pocas características comunes a otras ciudades latinoamericanas. Por ejemplo, la gentrificación en la GAM se produce más por redesarrollo, verticalización y recambio de stock edificado, y mediante la figura del condominio (horizontal y vertical), y menos por renovación urbana, proyectos de rehabilitación del patrimonio, intervención del casco histórico, proyectos turísticos, etc. En este punto, es ilustrativo lo hallado en el Tipo 3, justamente barrios céntricos, antiguos, que podrían renovarse, no reciben inversión inmobiliaria.

Siguiendo la literatura supracitada en el marco teórico, entendemos la captura de brecha de renta como el indicador visible o medible del proceso de financiarización de la economía y la mercantilización de las ciudades, los que generan las dinámicas inmobiliarias que llevan a la gentrificación, y que en Latinoamérica toman fuerza a partir de los cambios económicos y políticos estructurales ocurridos a partir de la década de 1980 . En nuestro país se verifica esta tendencia, y justamente las transformaciones 
en el modelo de gobernanza de la época, inician un estado de la situación en la que de alguna manera se impide la renovación, la rehabilitación y hasta el repoblamiento de los centros urbanos.

Ahora bien, estas condiciones no han detenido la gentrificación, sólo la han desplazaron a la periferia y, además, el nuevo reglamento de renovación urbana recién entró en vigencia, de manera que cabe esperar el inicio de nuevos procesos de gentrificación y el consecuente desplazamiento de población, ahora en la zona central de la ciudad.

De hecho, están en marcha algunos proyectos como obras de remozamiento de espacios públicos e infraestructura, por parte de la Municipalidad de San José. Y muy recientemente, de los últimos seis meses, nuevas torres de apartamentos.

Lo que hemos venido observando en la ciudad, es que, ante la ausencia de condiciones para la renovación urbana, hay procesos de verticalización y redesarrollo, no en áreas centrales, sino que es en barrios de clase media y alta del pericentro en donde el mayor tamaño de las propiedades permite al empresario inmobiliario una gestión más rápida que la que implicaría la negociación de compra-venta con un gran número de propietarios en el centro, en donde la propiedad privada del suelo es desconcentrada, de propiedades minúsculas que son el patrimonio de una gran cantidad de hogares. En estos barrios tradicionales de San José, se requeriría una normativa más agresiva de expropiación con declaratoria de renovación o patrimonio. $Y$ esto no lo promovemos como positivo, todo lo contrario, pero lo señalamos con el objetivo de llamar la atención sobre los barrios de clase media y alta que están verticalizándose: Escalante, Los Yoses y Dent. En estas mismas zonas, están ocurriendo importantes procesos de revitalización comercial y cultural.

Esto último abre preguntas sobre lo que sucederá en el corto plazo en el centro urbano, y merece una investigación posterior. Hasta la fecha, el modelo de gobernanza urbana heredado de los años 1980, ha marcado la tendencia de crecimiento de la ciudad: expansión, fragmentación y deterioro y abandono del centro.

\section{Referencias}

Asociación de Vecinos de Los Yoses (2017). Censo

Comunitario de Población, Vivienda y

Establecimientos. Documento de distribución limitada.

Banco Interamericano de Desarrollo (BID). (2017). Regeneración urbana de los Cuatro Distritos Centrales de San José. Recuperado de https://www.iadb.org/es/project/CR-T1160

Banco Nacional Hipotecario para la Vivienda (BANHVI). (2018). Ley del Sistema Financiero Nacional para la Vivienda No. 7052. Recuperado de: http://www.banhvi.fi.cr/quienes_somos/leyes_regl amentos/Ley7052_Dic17.pdf
Barquero, J. y Molina, W. (2014). Migración Intraurbana. Hacia un Nuevo Patrón de la Migración Interna en Costa Rica. Instituto Nacional de Estadística y Censos (INEC)-Costa Rica a la luz del Censo 2011, San José, Costa Rica.

Brenes, E. y Molina, W. (2013). Regeneración y repoblamiento de San José aún no llegan. Revista Ambientico (234), 15-25. http://www.ambientico.una.ac.cr/pdfs/ambientico/2 $\underline{34 . p d f}$

Brenner, N. (2013). Tesis sobre la urbanización planetaria. Nueva Sociedad, (243), 38-65.

Borja, J. y Castells, M. (2002). Local y global. La gestión de las ciudades en la era de la información. Madrid: Editorial Taurus. 
Carvajal, G. y Jorge, V. (1987). El surgimiento de un espacio urbano metropolitano en el valle central de Costa Rica. 1950-1980. Anuario de Estudios Centroamericanos (13)1, 71-94.

Casgrain, A. y Janoschka, M. (2013). Gentrificación y resistencia en las ciudades latinoamericanas. El ejemplo de Santiago de Chile. Andamios. Revista de Investigación Social, 10(22), 19-44. https://doi.org/10.29092/uacm.v10i22.265

CELADE (2006). Migración interna muestra signos de transformación. Santiago de Chile.

CELADE (2008). Migración y Desarrollo: el caso de América Latina. Informe compilado de las actividades de difusión: talleres nacionales y seminario internacional. Distribución limitada: Santiago de Chile. http://www.eclac.cl/cgibin/getProd.asp?xml=/celade/noticias/noticias/5/320 75/P32075.xml\&xsl=/celade/tpl/p1f.xsl\&base=/celad e/tpl/top-bottom.xsl

Contreras, Y. (2011). La recuperación urbana y residencial del centro de Santiago: nuevos habitantes, cambios socioespaciales significativos. Eure, 37(112), 89-113. https://doi.org/10.4067/s0250-71612011000300005

Contreras, Y. (2017). De los "gentries" a los precarios urbanos. Los nuevos residentes del centro de Santiago. Eure, 43(29), 115-141. https://doi.org/10.4067/s0250-71612017000200006

Chávez, A., Rodríguez, J., Acuña, M., Barquero, J., Macadar, D.; Pinto, J.M.; Sobrino, J. (2016) Migración interna y cambios metropolitanos: ¿qué está pasando en las grandes ciudades de América Latina? Revista Latinoamericana de Población (RELAP), 18(10).

De Mattos, C. (2005). Gestión territorial y urbana: de la planeación a la governance. Ciudades, (66), 2-9.

De Mattos, C. (2006). Modernización capitalista y transformación metropolitana en América Latina: cinco tendencias constitutivas. En Amalia Inés Geraiges de Lemos, Mónica Arroyo, María Laura Silveira (Eds.), América Latina: cidade, campo e turismo. San Pablo: Consejo Latinoamericano de Ciencias Sociales, CLACSO.
De Mattos, C. (2016). Financiarización, valorización inmobiliaria del capital y mercantilización de la metamorfosis urbana. Sociologias, 18(42), 24-52. https://doi.org/10.1590/15174522-018004202

Delgado, M. (2007). La ciudad mentirosa. Fraude y miseria del modelo Barcelona. Madrid: Los Libros de la Catarata.

Díaz, I. (2013). La gentrificación en la cambiante estructura socioespacial de la ciudad. Revista bibliográfica de geografía y ciencias sociales, XVIII(1030).

Díaz , I. y Salinas, L. (2016). La producción del consumidor. Valorización simbólica y gentrificación en el centro de la Ciudad de México. Revista Andamios, 13,(32), 107-130. https://doi.org/10.29092/uacm.v13i32.527

Ley № 4240 de Planificación Urbana (1968). Gobierno de la República, San José, Costa Rica.

Harvey, D. (1973). Social Justice and the City. España: Siglo XXI.

Harvey, D. (1985). The Urbanization of Capital. Baltimore: Johns Hopkins University Press.

Harvey, D. (2013). Ciudades rebeldes. Del derecho de la ciudad a la revolución urbana. Madrid: Akal.

Herrera, R. (2006). La perspectiva teórica en el estudio de las migraciones. Ciudad de México: Editorial Siglo XXI.

Instituto Nacional de Vivienda y urbanismo (INVU). (1983). Plan Regional Metropolitano GAM. Gobierno de la República, San José, Costa Rica.

Instituto Nacional de Vivienda y urbanismo (INVU). (2018). Reglamento de Renovación Urbana. Gobierno de la República, San José, Costa Rica.

Janoschka, M. (2002). El nuevo modelo de ciudad latinoamericana: fragmentación y privatización. Eure, 28(85), 11-20. https://doi.org/10.4067/s0250$\underline{71612002008500002}$

Janoschka, M. (2016). Gentrificación, desplazamiento desposesión: procesos urbanos claves en América Latina. Revista INVI, 31(88), 27-71. https://doi.org/10.4067/s0718-83582016000300002 
Klotchkov, V. (2001). Brevísima Historia De La Planificación Urbana De San José. Ambientico, (99), 46.

Lees, L., Slater, T., \& Wyly, E (2008). Gentrification. London: Routledge.

Lees, L., Shin, H., \& López-Morales, E. (2015). Global Gentrifications: Uneven Development and Displacement. Bristol: Policy Press.

Lees, L., Shin, H., \& López-Morales, E. (2016). Planetary Gentrification. Cambridge: Polity Press.

Lefebvre, H. (1970). La révolution urbaine. Paris: Éditions Gallimard.

Lefebvre, H. (1972). La pensée marxiste et la ville. Paris: Casterman.

López-Morales, E. (2009). Reseña de "Gentrification" de Loretta Lees, Tom Slater y Elvin Wyly. Revista de Geografía Norte Grande, (44), 155-158. https://doi.org/10.4067/s0718-34022009000300010

López-Morales, E. (2013). Gentrificación en Chile: aportes conceptuales y evidencias para una discusión necesaria. Revista Geografía de Norte Grande. (56), 31-52. https://doi.org/10.4067/s071834022013000300003

López-Morales, E., Gasic, I. y Meza, D. (2014). Captura desigual de renta de suelo y desplazamiento exclusionario. Indicadores generales del proceso de gentrificación en Santiago de Chile, 2000-2012. Cad. Metrop., São Paulo, 16(32),565-586. https://doi.org/10.1590/2236-9996.2014-3212

López-Morales, E. (2016). Acerca de una gentrificación "planetaria", políticamente útil. Revista INVI, 31(88), 217-240. https://doi.org/10.4067/s071883582016000300008

Ministerio de Obras Públicas y Transporte (MOPT). (2015). Encuesta de percepción sobre Ciudad Gobierno. Gobierno de la República, San José, Costa Rica

Ministerio de Vivienda y Asentamientos Humanos (MIVAH). (2007). Estudio Económico de la GAM, Diagnóstico Mercado de la Vivienda. Centro Internacional de Política Económica (CINPE), Universidad Nacional (UNA).
Ministerio de Vivienda y Asentamientos Humanos (MIVAH) y Cooperación Financiera de la Unión Europea. (2009). Plan Regional Urbano de la Gran Área Metropolitana (PRUGAM) 2008-2030. Gobierno de la República, San José, Costa Rica.

Molina, W. (2009). Patrones y flujos de la migración interna en la Gran Área Metropolitana de Costa Rica, en el período 1995-2000. Revista Población y Salud en Mesoamérica, 6(2). https://doi.org/10.15517/psm.v6i2.1602

Molina, W. (2013). Segregación Residencial Socioeconómica en la Gran Área Metropolitana de Costa Rica 1984-2000. Revista Población y Salud en Mesoamérica, 10(2).

Molina, W. (2019a). La gentrificación en Costa Rica: elementos para su estudio y comprensión. Revista de Ciencias Sociales, (164), 87-107. https://doi.org/10.15517/rcs.v0i164.38519

Molina, W. (2019b). Gentrificación en las zonas rurales de la GAM. Revista Ambientico, (270), 64-70. http://www.ambientico.una.ac.cr/pdfs/art/ambientic o/270 64-70.pdf

Molina, W. y Barquero, J. (2014). Migración Intraurbana. Hacia un Nuevo Patrón de la Migración Interna en Costa Rica. Costa Rica a la luz del Censo 2011. Instituto Nacional de Estadística y Censos (INEC), San José, Costa Rica.

Mora, M. y Solano, F.(1993). Nuevas tendencias del desarrollo urbano en Costa Rica: el caso del Área Metropolitana de San José. San José: Editorial Alma Máter.

Mora, J. (2003). Análisis del crecimiento urbano de la Gran Área Metropolitana de Costa Rica. Período 1983-2000 (Tesis para optar por el título de grado de Máster en Geografía). Universidad de Costa Rica, San José, Costa Rica.

Municipalidad de San José (MSJ). (2017). Boletín Informativo. Observatorio Municipal, (21), 1-20.

Pérez, M. (2005). Bosque Urbano: proyecto modelo de comunidad verde. El ejemplo de Los Guido-Orowe. Lincoln Institute of Land Policy. 
Pérez, M. (2012). Los impactos perversos de la segregación socioespacial en la ciudad de San José. En Mariam Pérez (Comp.), Avatares del ordenamiento territorial en Costa Rica. San José: FLACSO.

Rodríguez, J. (2001). Segregación residencial socioeconómica: ¿qué es?, ¿cómo se mide?, ¿qué está pasando?, ¿importa? Serie Población y Desarrollo, No. 16.

Rojo, F. (2016). La gentrificación en los estudios urbanos: una exploración sobre la producción académica de las ciudades. Cadernos Metrópole, 18(37), 697-719. https://doi.org/10.1590/2236-9996.2016-3704

Rosero, L. (2002). San José, desierto urbano. Éxodo y envejecimiento de la capital. Recuperado de: http://wvw.nacion.com/ln ee/2002/mayo/13/opinio n.html

Salinas, L. (2013). Gentrificación en la ciudad Latinoamericana. El caso de Buenos Aires y Ciudad de México. Geographos. Revista digital para estudiantes de Geografía y Ciencias Sociales, 4 (44), 283-307. https://doi.org/10.14198/geogra2013.4.44

Sassen, S. (1991). The global city, New York, London, Tokio. Princeton: Princeton University Press.

Sassen, S. (1994). Cities in a World Economy. Londres: Pine Forge Press/Sage Publications.
Sassen, S. (2007). Una sociología de la globalización. Buenos Aires: Katz Editores.

Sennett, R. (2004). El capitalismo y la ciudad. En Ramos, A. (Coord.), Lo urbano en 20 autores contemporáneos. Catalunya: Universitat Politècnica de Catalunya, Servicio de Publicaciones.

Silva, A. y Castillo R. (2007). Dinámicas metropolitanas en la era de la globalización: la promoción inmobiliaria en la ciudad de Sao Paulo, Brasil. EURE, 33(98). https://doi.org/10.4067/s0250-71612007000100003

Smith, N. (1979). Toward a theory of gentrification. A back to the city movement by capital not people. Journal of the American Planning Association, 45, 538-548.

Smith, N. (2012). La nueva frontera urbana. Ciudad revanchista y gentrificación. Madrid: Traficantes de Sueños, Colección Mapas.

Smith, N. (2015). El mercado contra la ciudad. Sobre globalización, gentrificación y políticas urbanas. Madrid: Traficantes de Sueños, Colección Mapas.

Solow, A. (1949). Proyecto para el desarrollo urbano de la capital de Costa Rica. Washington D.C.: Unión 